\section{Japan is cool to request to help pay to run CERN}

Tokyo. A recent suggestion by the head of the European Laboratory for Particle Physics (CERN) that Japan should contribute to the running costs of the Geneva-based laboratory has received a frosty reception.

Earlier this month, Carlo Rubbia, director-general of CERN, in a follow-up to two visits by CERN officials last year (see $\mathrm{Na}$ ture 359, 5; 1992), suggested that Japan should contribute 2.5 per cent of CERN's operating costs, or about SFr25 million (US\$18 million) a year, to compensate for the increasing number of Japanese users of CERN. Japan is not a member of CERN and does not contribute to its operating costs, although it has provided the laboratory with some equipment. In 1990, Rubbia hinted at such a request to physicists at Tokyo University.

In the past ten years, the number of registered Japanese users of CERN has increased eightfold (see figure). The Japanese presence is comparable to that of the Netherlands, a paying member of CERN, and larger than that of some other member nations such as Switzerland.

The United States, another non-member, has more users than Japan, but Rubbia says that its use of CERN is roughly balanced by comparable European access to US accelerator facilities. But few Europeans have been attracted to Japanese accelerators, and member nations of CERN are requesting that the balance be restored financially.

The 15-member accelerator subcommittee of Japan's Science Council, an advisory body to the Ministry of Education, Science and Culture, the ministry that funds Japan's participation in CERN, discussed Rubbia's proposal last week at a meeting covering several issues, including the US Superconducting Super Collider (SSC). Many on the subcommittee, chaired by the former director-general of the National Laboratory for High Energy Physics (KEK) in Tsukuba, Tetsuji Nishikawa, feel that Rubbia's request is "sudden and unreasonable", resulting from CERN's recent decision to allow Germany to reduce its contribution to the laboratory because of the costs of German reunification (see Nature 360, 701; 1992).

The subcommittee members say that paying to help run CERN would be unprecedented and would violate the principles of international collaboration in high-energy physics. They point out that operating costs in Japan do not include salaries, as they do at CERN, and that Japan pays the salaries of Japanese users. (However, the same is true of member nations who send scientists to Geneva.) Japanese users also point out that guidelines adopted in 1980 on interregional utilization of major facilities say that "operating laboratories should not require experimental groups to contribute to running costs". Japan believes that the number of Japanese users quoted by CERN overstates their participation, and points out that Japan has already contributed 30 per cent of the cost of the OPAL detector on the LEP electron-positron collider, which is used by Japanese scientists in Geneva.

Rubbia says that he would "much prefer" to reach a solution by evening up the exchange of scientists "rather than having money flow across borders". That would be made easier, he adds, if Japan proceeds with its plans to build a B-meson factory (see below). But some CERN member nations,

\title{
B-factory gets a boost
}

Tokyo. Plans to build a B-meson factory got a boost at last week's meeting of the accelerator subcommittee (see above). But the US Superconducting Super Collider (SSC) still casts a dark shadow over the future of the project.

The powerful subcommittee, which includes prominent professors from other fields outside high-energy physics, is supporting a proposal to build a B-meson factory at the National Laboratory for High Energy Physics (KEK) in Tsukuba rather than a plan to convert the main ring of the TRISTAN electron-positron collider at KEK into a gigantic synchrotron. The decision is a small victory for Japan's high-energy physicists, the majority of whom want the B-factory as Japan's next major project (see Nature 358 , $266 ; 1992$ ). The synchrotron, with a beam energy of $10 \mathrm{GeV}$, would have been the most powerful in the world and an important tool for those who analyse and fabricate materials.

The subcommittee's decision, in theory, allows the Ministry of Education, Science and Culture to request funds for the project in the ministry's fiscal year 1994 budget to be submitted in August. Only one thing stands in the way - the SSC. If Japan decides in the next few months to put money into the SSC, the ministry could not accommodate both projects in next year's budget.

D.S.

\section{Status of CERN visiting scientists}

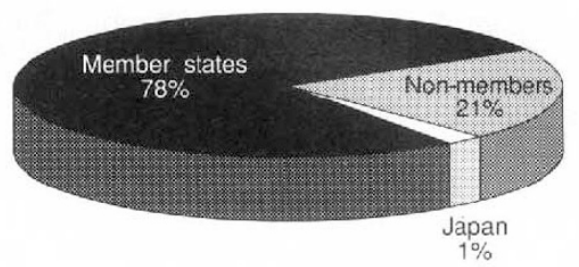

Japanese usage has grown

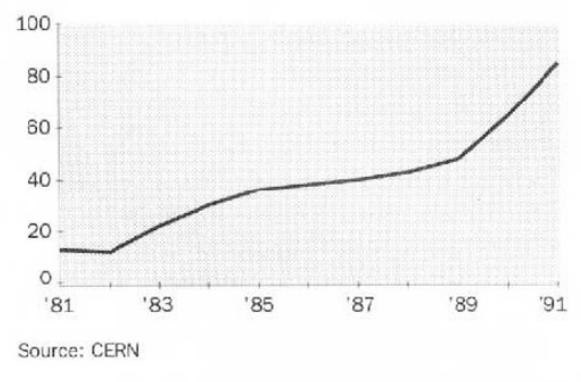

in particular Germany and France, are pressing for an immediate financial solution. The B-factory is "years down the road", says one European diplomat, who asks "how much longer are CERN member nations going to put up with people getting a free lunch?"

Another sticking point in the debate is Japan's role in funding the SSC. Europeans want to dissuade Japan from a joint consideration of their proposal and the SSC by emphasizing that they are seeking funds for Japan's current use of CERN and not for CERN's future Large Hadron Collider (LHC), a competitor of the SSC. But Japan believes the two issues are interrelated, and they do not plan to make a decision on CERN until they have an answer for US officials on their contribution to the SSC.

Akito Arima, president of Tokyo University and a member of the accelerator subcommittee, said in a letter to the subcommittee that a Japanese contribution to the SSC should be matched with one to CERN. "Everybody laughed", says one subcommittee member, "but I think everybody agreed".

In a related development from Washington, the Secretary of Energy in the Bush administration admitted to the US Congress shortly before leaving office last week that the department's campaign to attract foreign contributors to the SSC has fallen short of its goal. "Without a significant contribution from Japan", James Watkins wrote to US Representative George Brown (Democrat, California), "it is highly doubtful that the one-third foreign funding goal can be met." Watkins told Brown that only $\$ 45$ million of the planned $\$ 250$ million in non-federal contributions for next year has been obtained, part of a projected shortfall of $\$ 1.3$ billion by the SSC completion date in 1999 .

David Swinbanks 